\title{
Uveal melanoma: cell cycles and survival
}

The ability to predict the fate of patients after the removal of a neoplasm has remained a perpetual goal for pathologists. To accomplish this, the modern pathologist not only seeks to distinguish between benign and malignant tumours, but also to anticipate which of those frankly malignant neoplasms will pose the greatest threat to survival. To this end, various methods of classifying or staging a wide variety of tumours have been devised.

In 1931 Callender $^{1}$ devised a histological classification for uveal melanomas. Accordingly, tumours were divided into six groups: spindle cell $\mathrm{A}$, spindle cell $\mathrm{B}$, fascicular, mixed, epithelioid, and necrotic; based upon their cellular morphology or histological architecture. Subsequent studies have demonstrated the value of this classification in predicting patient survival. Paul et $a l^{2}$ in a retrospective study of 2652 melanomas of the ciliary body and choroid found that patients with spindle cell A tumours had a 15 year survival rate of over $80 \%$; in sharp contrast with patients with epithelioid tumours where the overall survival was less than $30 \%$. Although the Callender classification was universally accepted and has been used in its original form for many years, certain problems have emerged which have led to its eventual modification. A more recent classification divides melanocytic uveal tumours into three groups; spindle cell naevi, spindle cell melanomas, and mixed cell melanomas. ${ }^{34}$ While this modification is an undoubted improvement, a fundamental problem still remains - namely, it is subjective and relies entirely upon the judgment of the pathologist.

Several studies (albeit using the original classification) have emphasised the problem of interobserver error. MaLean et $a^{5}$ reviewed a series of 212 melanomas and found that they subsequently reclassified $12 \%$ of the tumours. Char et $a l^{6}$ found that two ocular pathologists affiliated with the same university classified. uveal melanomas differently $17 \%$ of the time! These discrepancies are hardly surprising: if a pathologist finds a single epithelioid cell in a field of spindle cells should he classify that tumour as of mixed cell type? Probably not. But what if the tumour contains five or 10 or 50 epithelioid cells per field? At what point should he make that crucial step and assign it mixed cell status? In an attempt to circumvent these problems ocular pathologists have investigated the role of quantitative techniques in assessing the metastatic potential of uveal melanomas. These efforts have focused on the morphology of the cell nucleus; for, while both cell shape and abundance of cytoplasm are factors in determining cell type, it is the appearance of the nuclei which is probably crucial in influencing the metastatic potential of the tumour. Gamel et $a l^{7}$ developed a computerised technique which randomly selected cells in a standard histopathological section; various measurements could then be made on the nucleus and its nucleoli. A number of these nuclear variables were found to correlate with patient survival. Further studies ${ }^{8}$ confirmed that the standard deviation of nucleolar area (SDNA), especially if combined with the measurement of the largest tumour dimension (LTD), ${ }^{9}$ was the most accurate quantitative cytological determinant of patient survival. Unfortunately, although measurement of the SDNA appeared to be a valid and reproducible method of assessing malignant potential, it was time consuming and required elaborate specially designed equipment. More recently, a simpler technique which determines the mean of the largest nucleoli (MLN) has been developed. ${ }^{10}$ While this method is undoubtedly less time consuming, it still requires an experienced technician to obtain the measurements.

Gross structural abnormalities of the nucleus reflect, at least in part, aberrations of the cell karyotype. The normal human somatic cell contains 46 chromosomes (23 pairs) and is referred to as diploid. A cell with fewer or more than 46 chromosomes is described as aneuploid. Karyotypic abnormalities are a well recognised feature of human cancers. The loss or gain of a chromosome may alter the amount of specific cell products and, if these are crucial in controlling cell division and differentiation, may lead to unrestrained proliferation. Furthermore, genetic abnormalities may lead to increasing karyotypic instability and a higher rate of spontaneous mutation which, in turn, will permit the more rapid progression to a highly malignant phenotype. ${ }^{1112}$ Recently, investigators have analysed the karyotypes of uveal melanomas and found non-random chromosome abnormalities. ${ }^{13-15}$ While karyotypic analysis may provide us with clues as to the initiating events in the development of neoplasms, it is extremely time consuming and requires fresh tumour tissue; for these reasons it is unlikely that it could be used routinely as a method of assessing prognosis. In contrast, flow cytometry is an automated method of quantifying the cellular DNA content of a tumour. In essence, a suspension of tumour cells is obtained and stained with fluorescent dye which will bind directly to DNA. This labelling is stoichiometric - that is, the degree of staining is directly proportional to the amount of DNA present. The suspension is then passed through a flow cytometer which can rapidly measure the amount of fluorescence, and hence the amount of DNA in an individual cell. The analysis of several thousand cells provides information about the ploidy and rate of cellular proliferation of the tumour. Studies in other human tumours using this technique have linked the presence of aneuploidy with poor prognosis. ${ }^{16}$ Several investigators $^{17-20}$ have utilised the technique of flow cytometry in an attempt to predict survival in patients suffering from uveal melanomas with mixed and conflicting results. Meecham and $\mathrm{Char}^{17}$ found that the presence and degree of aneuploidy was associated with reduced survival. Other authors have failed to demonstrate an association. ${ }^{18}$

In this issue of the $B \mathcal{B O}$ Hodge et al report their findings (p 521) using this technique on paraffin embedded material obtained from 45 posterior uveal melanomas. They found that the relative risk of death was approximately 3.5 times greater in patients with aneuploid tumours when compared with diploid ones. They also found that an increasing percentage of cells in S phase (an indicator of cell proliferation) was associated with reduced survival. They could not, however, demonstrate a relation between survival time and an increasing degree of aneuploidy. Their results are in broad agreement with the previously published results and suggest that, although this technique may have a role to play in determining survival in these patients, further work is required to confirm this. To date, with one exception, ${ }^{19}$ all studies have been retrospective using archival paraffin embedded tissue. Hodge et al emphasise the need for a standardised prospective study of flow cytometry using fresh tumour tissue: I endorse this proposal.

The search for accurate pathological determinants of survival in cases of uveal melanoma is a necessary one. There are, however, limitations: histological variation and genotypic aberrations do not predict the response of the host, if 
any, to the tumour; nor do they anticipate the impact of treatment on the eventual outcome. It is conceivable that timely intervention may prevent dissemination of a tumour, despite an apparently aggressive phenotype. Ultimately, a foolproof method of predicting survival may be unattainable. None the less the quest continues.

Department of Ophthalmology and Orthoptics,

IAN RENNIE

University of Sheffield,

Royal Hallamshire Hospital,

Glossop Road, Sheffield S10 2JF

1 Callender GR. Malignant melanocytic tumors of the eye. Trans Am Acad Ophthalmol Otolaryngol 1931; 36: 131-42.

2 Paul EV, Parnell BL, Fraker M. Prognosis of malignant melanomas of the choroid and ciliary body. Int Ophthalmol Clin 1962; 2: 387-402.

3 McLean IW, Zimmerman LE, Evans RM. Reappraisal of Callender's spindle cell A type of malignant melanoma of choroid and ciliary body. Am $\mathcal{F}$ Ophthalmol 1978; 86: 557-64.

4 McLean IW, Foster WD, Zimmerman LE, Gamel JW. Modifications of Callender's classification of uveal melanoma at the Armed Forces Institute of Pathology. Am F Ophthalmol 1983; 96: 502-9.

5 McLean IW, Foster WD, Zimmerman LE. Prognostic factors in small malignant melanomas of choroid and ciliary body. Arch Ophthalmol 1977; 95: 48-58.

6 Char DH, Crawford JB, Irvine AR, Hogan MJ, Howes EL. Correlation between degree of malignancy and the radioactive phosphorus uptake test in ocular melanomas. Am $₹$ Ophthalmol 1976; 81: 71-4.

7 Gamel JW, McLean IW, Greenberg RA, Zimmerman LE, Lichtenstein SJ. Computerized histologic assessment of malignant potential: a method for determining the prognosis of uveal melanomas. Hum Pathol 1982; 13: 893-7.

8 Gamel JW, McLean I, Greenberg RA, Naids RM, Folberg R, Donoso LA, et al. Objective assessment of the malignant potential of intraocular melanomas with standard microslides stained with hematoxylin-eosin. Hum Pathol 1985; 16: 689-92.

9 Gamel JW, Greenberg RA, McLean IW, Seddon JM, Albert DM, Naids $\mathrm{RE}$, et al. A clinically useful method for combining gross and microscopic measurements to select high-risk patients after enucleation for ciliomeasurements to select high-risk patients after
choroidal melanoma. Cancer 1986; 57: 1341-4.

10 Gamel JW, McCurdy JB, McLean IW. A comparison of prognostic covariates for uveal melanoma. Invest Ophthalmol Vis Sci 1992; 33: 1919-22.

11 Ohno S. Genetic implication of karyological instability of malignant somatic cells. Physiol Rev 1971; 51: 496-526.

12 Nowell PC. The clonal evolution of tumour cell populations. Science 1976; 194: 23-8.

13 Sisley K, Rennie IG, Cottam DW, Potter AM, Potter CW, Rees RC. Cytogenetic findings in six posterior uveal melanomas. Genes Chrom Cancer 1990; 2: 205-9.

14 Prescher G, Bornfeld N, Becher R. Nonrandom chromosomal abnormalities in primary uveal melanoma. I Natl Cancer Inst 1990; 82: malities

15 Sisley K, Cottam DC, Rennie IG, Parsons MA, Potter AM, Potter CW, et al. Non-random abnormalities of chromosomes 3,6 , and 8 associated with posterior uveal melanoma. Genes Chrom Cancer 1992; 5: 197-200.

16 Friedlander ML, Hedley DW, Taylor IW. Clinical and biological significance of aneuploidy in human tumours. $\mathcal{F}$ Clin Pathol 1984; 37: 961-74.

17 Meecham WJ, Char DH. DNA content abnormalities and prognosis in uveal melanoma. Arch Ophthalmol 1986; 104: 1626-9.

18 Shapiro BE, Felberg NT, Donoso LA, Augsburger J, Shields JA, Gamel J. Flow cytometry of uveal melanomas. Cancer Biochem Biophys 1986; 8: 235-8.

19 Rennie IG, Rees RC, Parsons MA, Lawry J, Cottam D. Estimation of DNA content in uveal melanomas by flow cytometry. Eye $1989 ; 3$ (Pt 5): 611-7.

$20 \mathrm{Char}$ DH. DNA cell cycle studies in uveal melanoma. Transactions of the American Ophthalmological Society 1989; 86: 561-80. 